\title{
ONTSTAAN, ROL EN BETEKENIS VAN DIE AFRIKAANSE KOERANTE
}

\section{Prof. G. P. Pienaar}

DIE koerant soos ons dit vandag ken, het pas 2000 jaar oud geword, nou wel nie altyd gedruk en met kleurfoto's versier nie, maar nietemin herkenbaar nuusblad. Ons dank vandag die Romein Cicero vir ons kennis van die heel oudste koerante. 'n Vriend, Marcus Caelius, het uit Rome aan dié veldheer laat weet dat ene Chretus in 'n met die hand geskrewe nuusblad die onaangename feit vermeld het dat Cicero se skoonseun, 'n swierbol met die naam Dolabella, sy huwelik met Cicero se dogter Tullia beëindig het en buitendien na Julius Caesar, Cicero se groot teenstander, oorgeloop het. Ons heel eerste kennis van die nuusblad gaan met ander woorde om ontrou, intrige en verraad. Hierdie resep ken die moderne koerant nog.

Met die hand geskrewe koerante het daarna 600 jaar lank in die Romeinse wêreld gesirkuleer, voortgebring deur vrymanne en slawe, soms behartigenswaardig, soms geniepsig, dikwels onbetroubaar, meermale erg eensydig en propagandisties, aan die begin baie onvolledig. Klein was hulle, want vermenigvuldiging met die hand gaan langsaam. Mossie was hulle, maar man - in die sin dat hulle miniatuur-prototipes was van die groot kanonne van vandag.

Dit was die Germaanse barbare wat in die sesde eeu ' $n$ einde aan die Romeinse Ryk gemaak het. Saam met die ryk se glorie het ook die koerant verdwyn. Daar het nie eens een behoue gebly nie, wel die inhoud van verskeie in ander manuskripte.

Nadat die wêreld so ses, sewe honderd jaar met vreugde sonder die steurnisse kon klaarkom wat deur koerante veroorsaak word, het die nuusblad in die laat middeleeue herleef, niemand weet presies wanneer nie, maar waarskynlik as een van die elemente van die Renaissance. Ook hierdie nuusblaaie wat onder vele name bekend was, is met die hand geskryf en vermenigvuldig. Regeerders en geleerdes, politici en koopmanne was die eintlike stukrag agter herlewing van die koerant. Ek beklemtoon spesifiek hierdie aspek omdat dit die wese en aard van die moderne koerant bepaal het. Dit is vandag nog die „base” van die koerant. En dan natuurlik die bloot nuuskieriger, die brood-en-spele-mense.

\section{Die drukpers}

Die heel oudste voorgangers van die drukpers het waarskynlik êrens in die dertiende eeu in Europa opgedaag, nou nie die groot mas iene wat vandag tot $\mathrm{R} 2$ miljoen stuk kos nie, maar klein, primitiewe goedjies wat met die sogenaamde blokdruk begin het. 'n Enkele woord oor blokdruk: by hierdie drukmetode word die hele bladspieël vooraf op hout of sagte metaal uitgesny of gegraveer en dan volledig afgedruk. By kleurdruk was 'n afsonderlike matrys vir elke kleur nodig. Eers teen 1440 het die Duitser Johann Gutenberg die Westerse wêreld geleer hoe om met bewegende los letters van metaal te 
werk.

Hoe primitief die ou blokdrukmetode ook al was: by die geboorte daarvan in Wes-Europa het die kerk en Satan bygestaan. Die heel oudste produkte vir die kerk was die sogenaamde Heiligen. Soos die naam aandui, was dit mooi stigtelike kleurprentjies met 'n minimum van skrif: die Europeërs van die laat middeleeue was naamlik nie juis indrukwekkend geletterd nie. Religieus was hulle betekenisvol. In my besit het ek twee van hierdie heiligen uit die vyftiende eeu - die engel en die herders en die laaste avondmaal, met Judas Iskariot gereed om sy brood in die skottel te doop.

Satan se aandeel was ewe kleurryk: speelkaarte waarmee die soldate, matrose en ander lui kon dobbel.

Kerk en wêreld het baie gou besef watter waarde die drukpers as strydwapen kan hê. Daar is heel vroeg met die druk van die sogenaamde Fliegende Blätter begin, die heel vroegste voorloper van die gedrukte koerant. Die naam kom van die feit dat reisende smouse en troebadoers bondels van hierdie geskrifte aan hul kraampies by kermisse en jaarmarkte geheg het waar hulle in die wind gewapper het.

In elk geval: deel van die inhoud van hierdie Fliegende Blätter was bloedstollende verhale van heksery en kettery. Die Fliegende Blätter is opsetlik deur die kerk in die groot heksejag van die vyftiende en sestiende eeu ingespan. Historici is dit eens dat mensevervolging voor die slagting van die Franse Revolusie en die latere Kommunistiese revolusies kort na die vestiging van die drukkersbedryf in Wes-Europa sy hoogtepunt bereik het.

En 'n tweede oogmerk: geniepsige aanvalle op die ,gekroonde hoofde" van ander state. Tussen 1573 en 1575 was dit vir die pous nodig om met drie bulle onder die nuusbladskrywers te laat gaffel.

As ons dus 'n les wil haal uit die vroeë drukpersgeskiedenis, dan is dit sonder twyfel dat die produkte van die drukpers met besondere welslae gebruik kan word om mense tot onheil en geweld aan te vuur.

Die teenoorgestelde is natuurlik ook waar: die gedrukte woord kan ook positief benut word in die diens van God en tot voordeel van die naaste. Mense wat so 'n bietjie sinies geword het, is egter geneig om te oordeel dat mense heelwat makliker tot onheil as tot deemoedige geloof opgewek kan word.

\section{Die koerant as propagandamedium}

Teen die tyd dat die gedrukte koerant in Wes-Europa sy beslag gekry het, was sy waarde as propagandamedium lankal bekend. Elizabeth I was teen die einde van die sestiende eeu al goed op hoogte met die waarde van gedrukte propaganda. In die godsdiensoorloë van die sewentiende en agtiende eeu het sommige militêre leiers hul eie koerante te velde gehad. In Engeland was dit die geval in die stryd tussen Cromwell en Karel I en in Frankryk het Lodewyk XIII en kardinaal Richelieu ywerig meegewerk aan die militêre en politieke propaganda wat deur die Gazette de France as amptelike koerant van Frankryk gevoer is. 
Uit hierdie tyd dateer die gebruik in Wes-Europa dat die kerke die sekulêre wêreld betree - die koppe van die Rooms-Katolieke Kerk het sedert baie vroeg in hierdie rigting gestaan, maar later het ook die Protestantse kerke in hierdie rigting beweeg. Doelwitte was in die besonder die perswêreld met koerante en tydskrifte, die skole en later ook die terrein van die politieke party en die vakbondwese. Dit is tot hede in Wes-Europa die geval. Alle partye wat die samestelling Christen-Demokrate in die naam dra, is RoomsKatoliek georiënteerd, terwyl daar in die moderne Nederland op sy minste nog drie betekenisvolle politieke partye is wat Gereformeerd van oorsprong was. U moet asseblief op die werkwoord in die verlede tyd let - was.

Dwarsdeur Europa was daar in die negentiende, selfs die twintigste eeu, koerante van formaat wat 'n maklik herkenbare godsdienstige standpunt gestel het. In die Dietse wêreld was daar min koerante van groter formaat, selfs gelyke formaat, as De Standaard van dr. Abraham Kuyper. In die moderne tyd is daar in Nederland nog 'n aantal kerkgebonde koerante, w.o. De Volkskrant (Katoliek), Trouw (Gereformeerd/Sosialisties), as daar van so 'n onding sprake kan wees, die Quartet, 'n losse groep van vier voormalige Calvinistiese blaaie, waarvan De Rotterdammer van dr. E. Diemer waarskynlik die belangrikste was. In Nederland is daar ook 'n aantal kerklike religieuse streekblaaie oor, bv. Friesch Dagblad, maar in die algemeen het „de ontzuiling" en televisie die religieuse pers in Nederland platgeslaan.

In Brittanje was die dagbladpers uit die staanspoor kerklik betreklik ongebonde. Daar was in Engeland weliswaar 'n neiging om die sogenaamde establishment, polities en religieus, te steun, maar dit het selde op meer neergekom as 'n ,goeie pers" vir die Konserwatiewe Party en die Anglikaanse Kerk. Kritici van die Anglikaanse Kerk het trouens al gesê dat hierdie kerk die „Conservative Party at prayer" is. Vandag is daar miskien rede om van die Anglikaanse kerk te praat as ,the Communist Party at prayer". Die Engelse pers is trouens lank deur manne van die establishment oorheers - ou families, die moderne persbaronne.

Om dan saam te vat: In die twee mees betekenisvolle stamlande van Suid-Afrika, Nederland en Brittanje, het die geskiedenis van die kerklike pers nie indrukwekkend verloop nie: in Nederland het die kerklike blaaie bestendig agteruit geloop, terwyl hulle in Brit$\tan$ e nooit werklik op dreef gekom het nie: in die moderne tyd trouens glad geen rol gespeel het nie. Waar kerklike koerante wel lewenskrag getoon het, was in die Katolieke lande waar die kerk in staat was om sy volle gewig agter die blaaie in te werp on lidmate as ' $t$ ware te dwing om daardie blaaie te koop en te lees. Dit was 'n verskynsel wat nooit in die vryer Protestantse wêreld noemenswaardig gegroei het nie.

\section{Die toestand in Suid-Afrika}

In Suid-Afrika het ons hierdie tradisie nooit geken nie. Die uitgee van koerante het in Suid-Afrika trouens bitter moeilik gevorder. 
Op net ' $n$ paar van die groot probleme moet gewys word:

1. Die geletterde bevolking was anderhalwe eeu so klein dat die plaaslike gemeenskappe nie koerante, massamedia, kon dra nie.

2. Die geletterde bevolking was totaal onvry, ondergeskik aan koloniale regerings in Nederland en Brittanje. Prof. Bouwke Spoelstra se proefskrif, Doppers in Suid-Afrika, lewer hiervan al die nodige bewyse.

3. Tot en met die koms van die Britse Setlaars was daar maar min Kapenaars wat in die koerantlees-tradisie opgegroei het. Die behoefte aan koerante was gevolglik klein.

4. Waar en wanneer daar wel behoefte aan massakommunikasie ontstaan het, het dit nie om die kerklike en religieuse gegaan nie, maar om die ekonomiese en die politieke laste van die burgery. Oor die godsdiens het die mense in Suid-Afrika eers in die tweede helfte van die negentiende eeu begin baklei.

Om dan weer saam te vat: toe die behoefte aan koerante wel teen die einde van die 18e eeu in die Kaap kenbaar geword het - die bevolking was toe ongeveer so groot soos dié van die huidige Potchefstroom - was die Hollandssprekende bevolking onderdane van 'n vreemde koloniale regeerder, yl en dun versprei, sonder koerantkennis en -behoeftes en klaar in die proses van afsondering deur taalonderdrukking.

\section{Eerste stappe}

In die laaste twintig jaar van die Nederlandse bewind het hier en daar 'n roerinkie kenbaar geword. Omstreeks 1783 het 'n man van Duitse afstamming, Johan Christiaan Ritter, met 'n klein drukpersie in die Kaap aangeland, maar hy moes tien jaar wag op toestemming om te kan begin druk. Twee jaar later was die Engelse hier en die Hollandse drukkerijtjie in die gedrang.

Die eerste koerant aan die Kaap is dan ook deur 'n Engelse firma gedruk. Die firma Walker en Robertson wat in gewone negosieware en slawe handel gedryf het en buitendien 'n kaperlisensie gehad het - dit was mos oorlog teen Frankryk - het die Cape Town Gazette and African Advertiser (Kaapsche Stads Courant en Afrikaansche Berigter) begin uitgee. Maar nie vir lank nie. Die Kaapse regering was bang dat selfs 'n Engelsgeoriënteerde koerant die burgery tot revolusie kon beweeg. En nog in dieselfde jaar, 1800, het die Kaapsche Courant 'n staatsblad geword, gevul met regeringsaankondigings, advertensies en ook 'n paar nuusbrokkies.

Dit was nie 'n indrukwekkende begin nie. Europa en die Verenigde State was toe al dik besaai met dagblaaie van formaat. Die oudste Engelse dagblad dateer uit die jaar 1705. Die Kaaps/Hollandse koerante het volgens die Britse tradisie begin waggel.

Die eerste gereelde uitgawe in Hollands aan die Kaap wat nie 'n regeringsblad was nie, was die tydskrif van dr. Abraham Faure, bekend as die Nederduitsch Zuid-Afrikaansche Tijdschrift, stalmaat van die vroeg gestorwe South African Journal van Greig en Pringle. Maar hierdie tydskrif wat meer as twintig jaar voortbestaan het, het 
hom bloot tot godsdienstige en stigtelike stof beperk. Dit het enduit sonder die kernelement van die koerant gebly.

Die gebrek aan belangstelling vir die koerantuitgewery en die klaarblyklike onhandigheid met hierdie moeilik hanteerbare medium blyk daaruit dat die eerste twee uitgewers van Nederlandsgeoriënteerde (hoewel tweetalige) partikuliere koerante 'n bekeerde Amsterdamse Jood van Portugese afkoms, Josephus Suasso de Lima, en sy opvolger die Fransman Charles Etienne Boniface was. Die eerste betekenisvolle hoofartikelskrywer was ook 'n Fransman, dr. A. N. E. Changioun, wat egter in Nederland gebore is, en wel uit Hugenoteouers.

By al die Hollandse koerante wat in die negentiende eeu in Kaapland gekom en gegaan het, was teoloë net een keer prominente deelhebbers. In 1861 het dr. Servaas Hofmeyr, 'n predikant van die N.G. Kerk, en proff. N. J. Hofmeyr en J. H. Neethling, van die Kweekskool, hand bygesit met die stigting van De Volksvriend, mondstuk van die "Orthodokse party" teen die opkomende liberalisme, vrug van die angliseringsbeleid soos die koloniale regering dit ook op kerklike erf toegepas het.

By die stigting van Di Patriot in 1875 was ds. S. J. du Toit weliswaar ook voorbok, maar Di Patriot was nie in die eerste plaas draer van uitsluitend religieuse oogmerk nie. Dit is opgerig om kerk en taal en volk te dien.

Maar ook De Volksvriend het nie lank sy intieme verband met die teoloë behou nie. Onze Jan Hofmeyr, wat op ouderdom sestien by die nuwe blad begin werk het, was op sewentien reeds redakteur en op negentien reeds eienaar. De Volksvriend was met ander woorde net soos Di Patriot nooit werklik 'n kerklike blad nie.

B. J. van de Sandt de Villiers se Het Volksblad (vir die eerste keer in 1849 uitgegee) het in die sestiger jare ywerig aan die stryd tussen liberalisme en ortodoksie deelgeneem, maar dit was 'n politieke eerder as 'n kerklike blad. By die stigting van alle latere Afrikaanse koerante het politici, en nie kerkmanne nie, die hoofrol gespeel. Dikwels was daar 'n noue verbintenis, dr. Malan en Die Burger, maar die eerste oogmerk was politiek en volk, nie kerk nie.

Op die terrein van die tydskrif het die kerke 'n meer positiewe rol gespeel. Afgesien van De Zuid-Afrikaansche Tijdschrift verskyn in 1833 De Kaapsche Cyclopedia, in 1837 Leesvruchten, in $1838 \mathrm{De}$ Honigby van dr. Faure, in 1849 De Kerkbode. Met die koms van die Geref. Kerk en die Hervormde Kerk het nuwe tydskrifte as lyforgane ontstaan. Oor die tans nog bestaande kerklike tydskrifte hoef nie uitgewei te word nie.

\section{Betekenis vir die kerk}

Hoewel die kerke in Suid-Afrika - aan weerskante van die taalgrens - nooit in die geskiedenis werklik koerantstigters was nie, beteken dit nie dat die Suid-Afrikaanse koerante onverskillig teenoor die kerke gestaan het nie. Daar is histories baie sterk bande tussen die Afrikaanse kerke en die Afrikaanse koeranțe. Trouens, 'n Afrikaanse redakteur sou onnosel wees as hy met die Afrikaanse kerk rusie 
maak: sy lesers is oorweldigend lidmate van die Afrikaanse kerke.

Maar in werklikheid was die bande in die verlede - en miskien nou nog - sterker as wat bloot deur ekonomiese oorweginge ingegee word. Dit kan nie weggeredeneer word dat kerk en party en pers in die verlede meesal medestryders was, elk op sy eie terrein, in belang van die Afrikaanse volk en sy geestesgoed. Wanneer sake in die verlede krapperig geraak het, bv. in die Voortrekkertyd en weer tydens die rebellie, om maar twee voorbeelde te noem, was dit omdat ernstige politieke en staatkundige geskille tussen kerk- en volksleiers ontstaan het. Maar hierdie breuke is in die verlede meesal betreklik gou geheel.

Miskien kan die kerk/volkverhouding in Suid-Afrika die beste soos volg opgesom word: Geen langdurige breuke het nog in SuidAfrika tussen kerke (of groot deel van kerke) en die Afrikaanse volk (of 'n groot gedeelte daarvan) voorgekom nie. In die verlede het wel vir korter of langer tye stryd in die pers oor kerklike aangeleenthede gewoed (in die sestiger jare van die vorige eeu en die twintiger jare van ons eeu), die Du Plessis-era, maar dit het nooit tot 'n volkome breuk gelei nie. Inteendeel, kerk en pers het nog steeds bevrugtend op mekaar ingewerk.

Dat daar ook verskille en geskille gekom het, dat daar oor en weer vermaan en betig is, is ewe waar. Maar meesal was die gees waarin probleme en verskillende sienswyses uitgestryk is, nog Christelik broederlik. Oor wat in die toekoms gaan gebeur, sal dr. Willem de Klerk meer sê. Hy staan nou nader aan die vuur as ek.

\section{Slotopmerkinge}

Vir my was dit nog nooit 'n deugdelike saak dat die kerk as instituut formeel met buitekerklike instellinge soos die pers, politieke partye, dalk selfs die skool, formeel verbind staan nie. Die primêre taak van die kerk bly na my mening die verkondiging van die evangelie, 'n taak wat die kerk nie altyd na behore kan verrig as hy naderhand kniediep in sekulêre probleme beland nie.

Die politieke party het te doen met die moontlike, al skiet dit soms, liewer dikwels, kort by die Christelike behorensmatige. Die politiek kan kompromieë maak, die uitvoering van sekere take, bv. die uitroep van die republiek in Suid-Afrika, 'n tyd lank op die ys hou. Maar die kerk mag nie kompromieë maak nie. Hy mag nie ophou om te getuig nie. In die Westerse wêreld is daar te veel luide waarskuwings oor hierdie aangeleentheid dat ons dit in Suid-Afrika nie raaksien nie.

In die meer as 'n kwarteeu dat ek aktiewe joernalis was, later by uitstek politieke joernalis, sien ek vir die kerk ewe groot probleme. Die kerk en die pers arbei albei in 'n verskeurde en sondige wêreld, maar hulle werk nie eenders nie. Al sou die geloofsnorme van die kerk en die koerant ook nie verskil nie, verskil die arbeidsnorme, die werkwyse, die benadering ingrypend. Ons eie geloofsgenote in Nederland op die terrein van die kerk en die pers waarsku ons eweneens luid: Handhaaf tot elke prys die soewereiniteit in eie kring, want daarin lê die waarborg vir die vryheid van albei. 
Die kerktradisie en die koeranttradisie verskil hemelsbreed.

'n Laaste opmerking: van hul kant kan die Afrikaanse kerke gerus 'n poging aanwend om die koerante met groter blyke van handigheid te benut. Die gesindheid tussen die koerante en die kerke is dikwels suur, en as getroue kerkman wil ek dit duidelik stel: kerkleiers is dikwels nie van haas ongelooflike onbeholpenheid vry te spreek nie.

(Gelewer voor die Jaarlikse Saamtrek van die G.T.V. te Pretoria, 10 Junie 1975.) 